\title{
Study of Congenital Neurological Anomalies in Foetus
}

\author{
I.Rajashree ${ }^{1}$, T. Sobha devi ${ }^{2}$ \\ ${ }^{1}$ Associate professor, Department of anatomy, osmania medical college, Hyderabad, NTRUHS, A.P, India \\ ${ }^{2}$ Assistant professor, Department of Anatomy, S.V.Medical college, Tirupathi,NTRUHS, India
}

\begin{abstract}
Congenital defects and anomalies present at birth have induced curiosity in people, since the dawn of history. In early societies, the babies surviving with developmental defects were considered as Monsters and were thought to be a curse on the mother or family. Prehistoric period reveals the records of human congenital malformations in cave paintings, sculptures and in writings. Archeologists have found skeletons of malformed infants dating as far back as the Stone Age. In the dark middle ages, mothers were burnt for the alleged curse of giving birth to a malformed child. The present study was done on 50 still born and aborted fetus around age group of 26 weeks to 40 weeks obtained from Gandhi Hospital Secunderabad,6 of them had central nervous system abnormalities of anencephaly to spina bifida, 1case of meningocele. The author found a high incidence of central nervous system anomalies which suggest that they may be due to nutritional defiencies like folic acid and vitamin B 12 as the present study involved people from rural areas around Hyderabad and Secunderabad in a low socio economic group.
\end{abstract}

Key Words: Anencephaly, meningocoel, spina bifida, foetus

\section{Introduction}

Knowledge of embryology ,teratology, clinical genetics and diagnostic ultrasonography have paved way to identity the anomalies and treat them successfully in pre/postnatal phase .Tremendous advancement in the imaging technique and availability of sophisticated instruments have made prenatal fetal surgery to repair many of the anomalies possible - an unimaginable dream co In this era where family planning has been accepted by all. It is imperative to take measures to identify anomalies during prenatal phase, so that in cases of major anomalies, MTP can be advised to avoid economic burden and domestic difficulties to the parents. At present teratogens in the form of pathogens extensive chemicals used in day-to-day life and drugs consumed by the mother have resulted in the increased incidence of anomalies.

The primary importance to examine the malformed foeti is to derive more information which can be used to counsel parents in respect of future pregnancies .Understanding the etilogical factors in the causation of anomalies definitely plays an important role in the prevention. Early detection and excellent surgical management has resulted in the children reaching better adulthood with better life expectancy.Hence the present study is undertaken to throw more light if possible on the subject by studying autopsy finding. These babies and internal anomalies were studied in detail and photographs were taken wherever necessary.

\section{Material And Methods}

The present study was done on 50 still born and aborted fetus around age group of 26 weeks to 40 weeks obtained from Gandhi Hospital Secunderabad. The fetuses were brought to the department of Anatomy Gandhi Medical College Secunderabad. They were thoroughly cleaned, numbered and prepared for study. A detailed examination of external features was performed. Sex of the fetus was recorded and the length of each specimen was measured.

The head was examined for details like extent of absence of bones of skull, state of development of eyes. The morphology of the nose studied. Apart from these the ears tongue, mouth, lips, palate and lower jaw were thoroughly examined. The state of development of neck was recorded next.

The region of the vertebral column that is the midline region on the back of the trunk was carefully observed for any discontinuity. Examination of the external features was followed by dissection of the fetus to study viscera in the thorax and abdomen. A midline incision was taken form the lower lip to the pubic symphysis. Skin flaps were separated; symphysis menti and sternum were cut in midline and separated to expose the viscera. 


\section{Results}

Table .1, figures.1, 2,3,4,5 shows the observations

Table no. 1 Summary of observations

\begin{tabular}{|l|c|}
\hline \multicolumn{1}{|c|}{ Case no } & Normal/abnormal \\
\hline $1,2,3,4,5,6,7$ & No CNS anomaly \\
\hline 8 & $\begin{array}{c}\text { Male Anencephlic fetus, brain not developed, } \\
\text { skull bones not developed, protruding eyes }\end{array}$ \\
\hline $9,10,11,12,13,14$ & No CNS anomaly \\
\hline 15 & $\begin{array}{c}\text { A case of female with anencephaly, spina bifida, } \\
\text { brain not developed, skull bones not developed, } \\
\text { protruding eyes, vertebral column deformed upto } \\
\text { T12 level(spina bifida) }\end{array}$ \\
\hline $16,17,18,19,20$, & No CNS anomaly \\
$21,22,23,24,25,26$ & Male foetus with Hydrocephalus \\
\hline 27 & No CNS anomaly \\
\hline $28,29,30,31$ & Male foetus with Bilateral cleft lip,cleft palate, \\
& anencephaly \\
\hline 32 & No CNS anomaly \\
\hline $33,34,35,36,37$ & Male foetus with meningocoel, gastroschisis \\
\hline 38 & No CNS anomaly \\
\hline $39,40,41,42,43$, & Female foetus wirh Anencephaly, spina bifida \\
\hline 44 & No CNS anomaly \\
\hline $45,46,47,48,49,50$ &
\end{tabular}

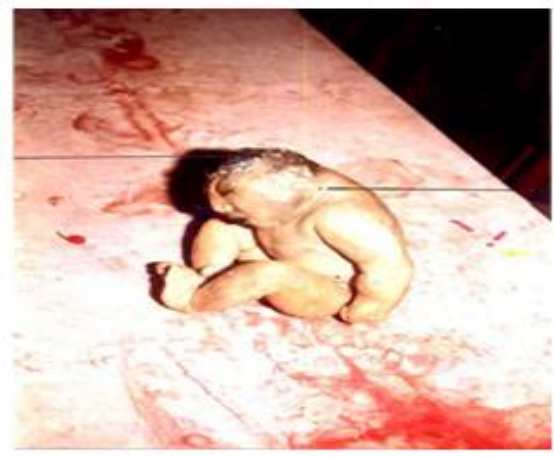

Fig.1 Male Anencephlic fetus, brain not developed, Skull bones not developed, protruding eyes

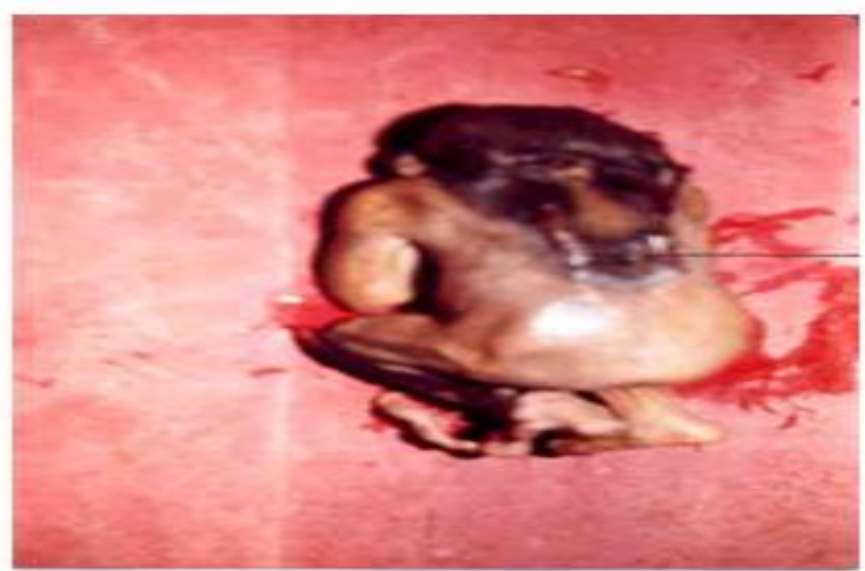

Fig. 2 A case of female with anencephaly, spina bifida,

Brain not developed, skull bones not developed, protruding eyes, vertebral column 


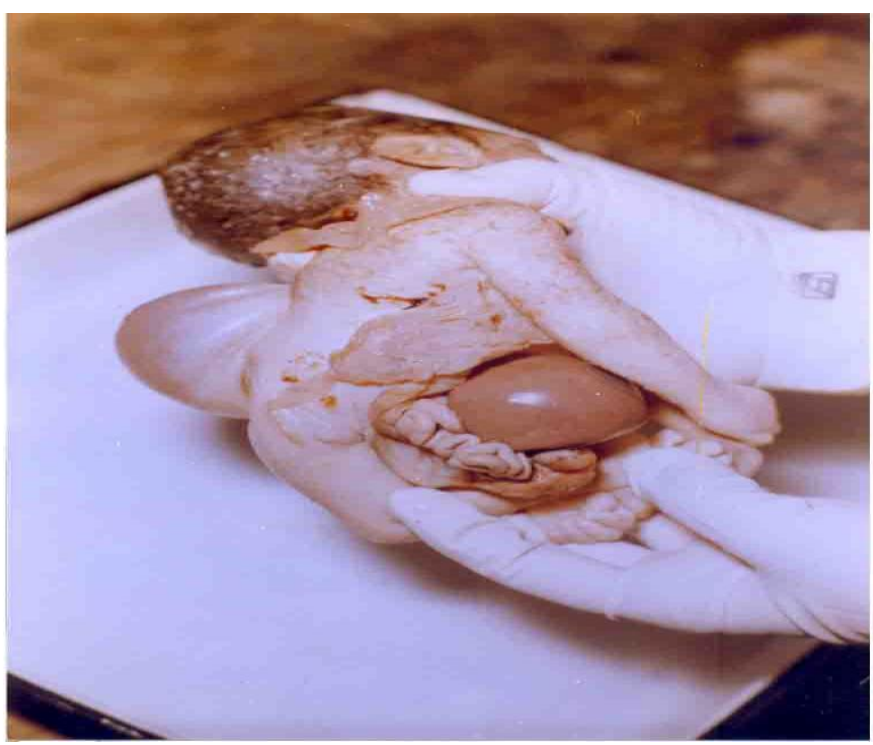

Fig.3.male foetus with Bilateral cleft lip, cleft palate, anencephaly

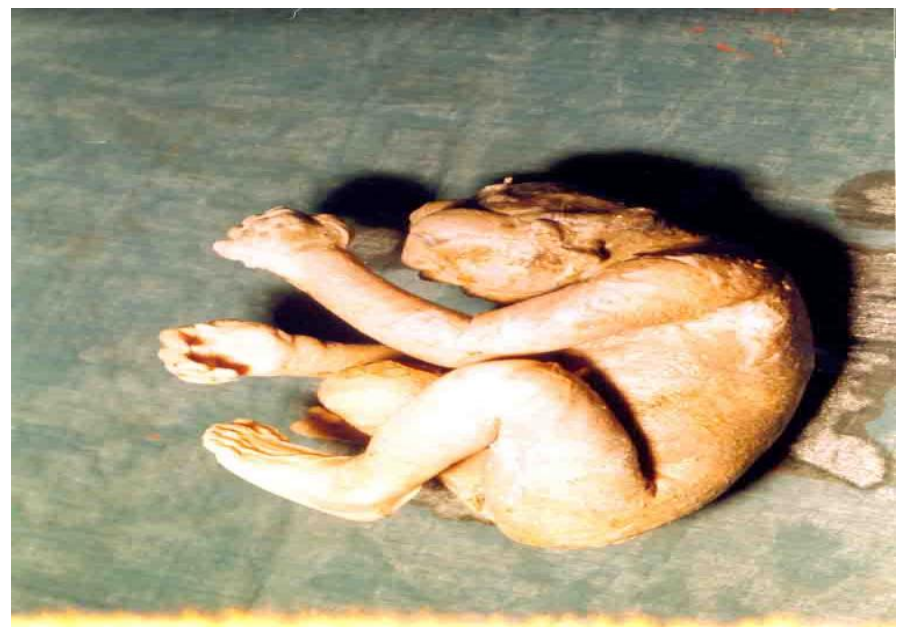

Fig.4. male foetus with meningocoel, gastroschisis

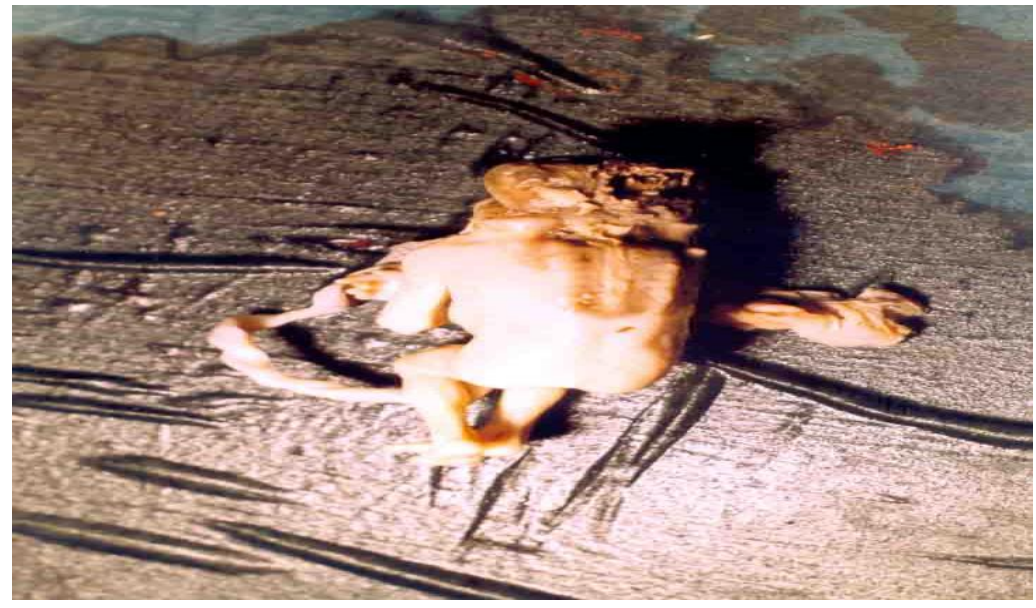

Fig.5.female foetus with Anencephaly, spina bifida 


\section{Discussion}

In the through search of the past literature abnormalities of the central nervous system were reported to be 5.9 per 1000 live births as reported by Coffvi and Edwards in 1957(ref.2). The incidence observed by the present astudy is at higher side i.e., $12 \%$ in which the has dissected 50 -still born and aborted fetus and found 6 of them had central nervous system abnormalities of anencephaly to spina bifida.

Muffarij(ref 4) in 1963 found that 2 out of 1000 births were anencephalies ranging.2\%but the present study shows a quite high range of $4 / 50$ i.e., $8 \%$ anencephalic fetuses.

Aiyar(ref 1) in 1969 reported 1 case of meningocele.In the present study also 1 case of meningocele was found. Vare and Bansal(ref 7) In 1971, reported cases of central Nervous system abnormalities in which they noticed 3 cases of spine bifida per 1000 cases i.e., .3\% of. They noticed that 6 of the cases of spina bifida extended through out the length of the vertebral column. Aiyar also reported a case of spina bifida where the spinal cord was exposed up to the lower lumbar region.In the present study the noticed 1 case out 50 specimens ranging $2 \%$, which is extending up to $\mathrm{T}_{12}$ level.

Vogel and Maclenahal(ref 8) in 1957 also reported 14 Anencephalic cases in which they reported that spinal cord was found to be of normal size. Present study has found 4 cases of anencephaly were spinal cord is normal in 2 cases i.e., is Fig A8 \& Fig .A32 and spina bifida in 2 cases i.e., Fig. A15 \& Fig. A 44.

4 out of 40 cases i.e., $10 \%$ as found by Tamsel zbeb(ref 6) in 2004, by using MR imagining had central nerves system abnormalities. In the present study found a similar incidence 6 out of 50 specimens i.e., $12 \%$. The incidence reported by Comerford(ref 9) was 6.5 per 1000 were Anencephlic.

Table 2 COMPARISION OF CENTRAL NERVOUS SYSTEM ABNORMALITIES

\begin{tabular}{|c|c|c|c|}
\hline S.No & Authors & C.N.S & Percentage \\
\hline 1 & Tamsel.S. Ozbek & $4 / 40$ & $10 \%$ \\
\hline 2 & Lammer & $18 / 21$ & $85 \%$ \\
\hline 3 & Coffvi \& Edwards & $5.9 / 1000$ & $0.59 \%$ \\
\hline 4 & Muggariji \& Kilijam & $2 / 1000$ & $0.2 \%$ \\
\hline 5 & Vogel \& Meclenahan & 14 & $0.6 \%$ \\
\hline 6 & Comerford & $6.5 / 1000$ & $0.5 \%$ \\
\hline 7 & Seluck & $.5 / 1000$ & $0.3 \%$ \\
\hline 8 & Vare \& Bansal & $3 / 1000$ & $12 \%$ \\
\hline 9 & Present author & $6 / 50$ & \\
\hline
\end{tabular}

\section{Chart 1}

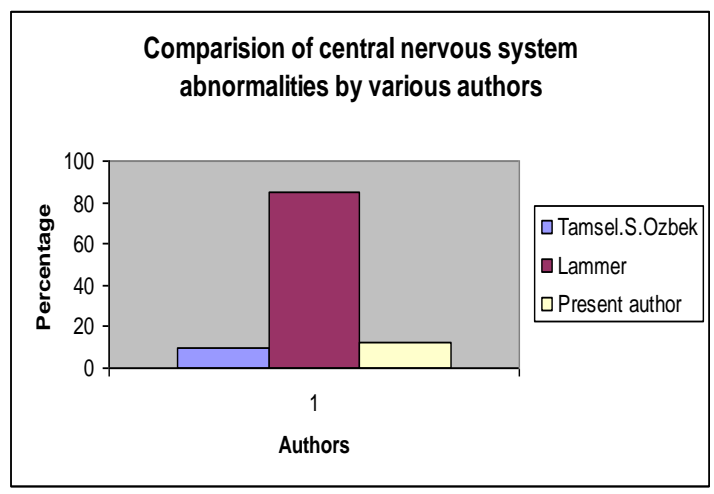

V. Conclusion

The study found a high incidence of central nervous system anomalies which suggest that they may be due to nutritional defiencies like folic acid and vitamin B 12 as the present study involved people from rural areas around Hyderabad and Secunderabad in a low socio economic group. The present author is interested to continue further study of congenital anomalies by using ultrasonogram and early detection of chromosomal anomalies and by advance molecular genetic studies in the pregnant women in the early gestational age so that a proper timely advice can be given to have a healthy and normal child 


\section{References}

[1]. Aiyer P.R. (1969) congenital malfarmations. Paediatric clinic of India Volume No: 4 October: 369-371.

[2]. ,Coffvi .V.P. and Jessop .W.J.E. a study of 137 cases of anencephaly Brit. Preventive Medicine (1957) 11:174-180

[3]. Lammer 1985 in fetal congenital Anomalies -an analysis Americal Journal of Obstretics \& Gynaecology 1985 $91: 870$.

[4]. Muffarij .I.K, and Kilejan, V.O. Anencephaly-an analysis of anencephalic births 1963, 22:257.

[5]. Seluk Eruz and Theodore .M.King anencephaly a survey of 44 cases. Obstretics \& Gynaecology 1966 27: 601

[6]. Tamsel .S. Ozbek.SS .Senar.Rn, Oztekin .O, Demipolat .G. Department of Radiology . Bornova comparative medicine imaging Graph 2004 April 28 (3) (4)-9.

[7]. Vare AM and Bansal P.C An anatomical study of congenital anomalies. Indian journal of Paediatrics 1971, $38: 301$.

[8]. Vogel Stephen .F and Macclenahan .L, Anomalies major cerebral vessels and associated congenital malformations . American journal of Pathology 1952, 28:70, -723.

[9]. Commenford. J.Pregnancy with congenital anomalies Lancet X.1965 Cited by Vare-Banasal. 